\title{
MEDITAR A CONTRAPELO: CARÁCTER Y NACIÓN EN LA ANTROPOLOGÍA HISTÓRICA DE JULIO CARO BAROJA
}

\author{
Enrique SANTOS UNAMUNO \\ Universidad de Extremadura \\ ensantos@unex.es
}

Gentium itaque ac populorum ingenia tum ex historiis, tum ex proverbiis atque ex ore vulgi excipienda censeo

Julius Caesar Scaliger, Poetices libri septem

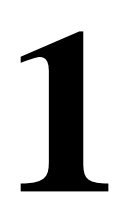

\section{Introducción}

El presente trabajo se inserta dentro de una línea de investigación comparatista que en otra sede denominamos ImageNation Studies (Santos Unamuno 2009), al fin de distinguirla en parte de la tradición imagológica de la primera mitad del siglo XX y ponerla en relación con los Image Studies de base centroeuropea cultivados a partir de mediados de la década de 1960 por la escuela de Aachen (con Hugo Dyserinck a la cabeza) y continuados por autores como Joep Leerssen ${ }^{1}$. Los tres vértices que articularían dicho campo son las nociones de estereotipia, carácter y nación (abordables más bien en cuanto constelaciones de problemas teóricos e históricos), consideradas centrales a la hora de entender el hecho literario europeo en sus diferentes épocas y en su compleja configuración sistémica. Asimismo, el punto de partida de las siguientes páginas puede rastrearse en el interés por los mecanismos de base estereotípica presentes en la formación de autoimágenes y heteroimágenes en cuanto constructos históricos fundamentales a la hora de encarar la constitución de las modernas identidades nacionales europeas, como ya tratamos de demostrar en nuestro acercamiento a las guerras simbólicas desencadenadas en torno a la definición de la imagen de España en los estudios históricos y literarios entre 1990 y 2006 (Santos Unamuno 2006) y en nuestro anterior análisis del concepto de estereotipia en la obra del antropólogo e historiador Julio Caro Baroja (Santos Unamuno 2011). En esta ocasión, como ulterior ejemplo de la necesidad de abordar estudios históricos concretos acerca de la propia evolución de las ciencias sociales y humanas en sus contextos culturales y nacionales de

\footnotetext{
${ }^{1}$ Como es obvio, el campo teórico de la imagología comparatista es mucho más complejo que todo eso y la nómina de autores relevantes mucho más extensa (piénsese, por citar sólo unos pocos, en Daniel-Henri Pageaux, Jean-Marc Moura, Alain Montandon, Maria Jõao Simões o Paolo Proietti). Sin embargo, no es ésta la sede adecuada para una cumplida discusión en lo que atañe a dicha cuestión. Las dos mejores visiones de conjunto teóricas e históricas a un tiempo de los estudios imagológicos son, a nuestro juicio, la ofrecida por Manfred Beller y Joep Leersen (2007) y por Paolo Proietti (2008).
} 
aparición, analizaremos de forma sucinta el importante papel desempeñado por el concepto de carácter en cuanto piedra de toque teórica a la hora de abordar los procesos de construcción de las identidades individuales y colectivas en la obra de Caro Baroja. A través de dicho análisis, trataremos de poner de relieve el complejo y conflictivo trasfondo nacional presente en la elaboración y manejo de dicho concepto por parte del autor.

\section{La idea de carácter en Julio Caro Baroja: discursos contra la nación}

Trazar en pocas palabras la semblanza personal y profesional de Julio Caro Baroja (1914-1995) se presenta a todas luces como una empresa casi imposible. Bástenos decir aquí que sus múltiples intereses y capacidades llevaron a este humanista global a cultivar indistintamente disciplinas como la Antropología, la Historia, la Etnología, la Lingüística, la Geografía o los estudios literarios, dando lugar a una ingente obra caracterizada sin duda por lo que algunos han denominado una «apariencia de felix diversitas» (Cid 1989: 68). Testigos de esa felicidad fueron reconocimientos públicos tan señalados como el Premio Príncipe de Asturias de Ciencias Sociales (1983), el Premio Nacional de las Letras Españolas (1985) o el Premio Internacional Menéndez Pelayo (1989), entre otros. En realidad, su independencia política y científica, su carácter indisciplinado e interdisciplinar (tan opuesto a los conventillos universitarios) y su ubicación a caballo entre Historia y Antropología, han supuesto «el aislamiento de una obra que, precisamente por no querer pertenecer a una sola parte, ninguno de los grupos profesionales implicados ha acabado por asumir» (Carreira/Ortiz 1998: X). En lo tocante a nuestro discurso, diferentes autores han subrayado la centralidad de las cuestiones identitarias en la obra de Caro Baroja, especialmente las relacionadas con las identidades culturales de los pueblos de la Península Ibérica. Así, Davyyd Greenwood ha hecho hincapié en el interés de nuestro autor por deconstruir las implicaciones políticas de muchas construcciones antropológicas, su empeño en demostrar que, más allá de su aparente monolitismo, «estas identidades son históricamente falsas, internamente heterogéneas y, a menudo, idealizadas» (Greenwood 1989: 18). Otros autores, al elencar la serie de temas clásicos de Caro Baroja, mencionan «los tópicos en torno al carácter, los modos de vida y la historia nacional» (Carreira/Ortiz 1998: X). Por su parte, en la introducción a una reciente reedición francesa del célebre trabajo «El mito del carácter nacional y su formación con respecto a España» (1970), del que nos ocuparemos más adelante, Bernard Traimond recalcaba la importancia del análisis diacrónico de las representaciones colectivas y sus proyecciones identitarias en el periplo investigador de Caro Baroja. Identificaba además las nociones de arquetipo (estereotipo) y carácter como el fulcro de su obra, «el tema que le ha perseguido toda la vida» (Traimond 2004: 25). El papel desempeñado en el proyecto antropológico de Julio Caro Baroja por el concepto de carácter, una de las plasmaciones de la tendencia cognitiva humana a la identificación esquemática y la estereotipia, será el objeto de las siguientes reflexiones. 


\section{1. Hacia una antropología de los pueblos históricos}

En primera instancia, es preciso insistir en la posición excepcional (y pionera) de nuestro autor respecto a corrientes hegemónicas de la antropología europea y norteamericana como el evolucionismo, el funcionalismo o el estructuralismo, que no cesó de criticar a lo largo de su obra. El origen de sus posiciones antropológicas es sin duda el magisterio kantiano, como reconocía el propio autor, que se refería al solitario de Königsberg como «el filósofo que desde un punto de vista crítico, limitado, más me ha influido, desde los días de la juventud» (1985b: 19). En efecto, los dos primeros capítulos de Los fundamentos del pensamiento antropológico moderno (1985), una personal visión de la evolución histórica de la disciplina, están dedicados a la figura de Kant y a la glosa admirada de las lecciones dispersas (1772-1795) que acabarían confluyendo en el volumen Anthropologie in pragmatischer Hinsicht (1798). Los principales elementos kantianos aprovechados por nuestro autor serán, según él mismo admite, la noción de esquema o plan (la base de su teoría del arquetipo y del carácter), el uso de la literatura, los libros de viajes, la historia o la biografía como fuentes del estudio antropológico y el interés prioritario por los pueblos históricos europeos frente a la tradición antropológica centrada en el trabajo arqueológico o de campo sobre aquellos que Johann Gottfried Herder y Theodor Waitz denominaron Naturvölker o pueblos naturales (Caro Baroja 1985b: 11-29). En su breve resumen de la Anthropologie, Caro Baroja se refiere a la distinción kantiana entre una vertiente física de la Antropología, centrada en el conocimiento de las razas humanas, y una perspectiva antropológica pragmática (así reza el título del libro), centrada en el estudio «de los caracteres de pueblos y naciones» (1985b: 25) y más cercana al proyecto antropológico del propio filósofo. Por otra parte, si el volumen de Kant se dividía en una «Didáctica» y una «Característica» antropológicas, será sin duda este segundo bloque el punto de arranque de la labor investigadora del propio Caro Baroja ${ }^{2}$. En efecto, el autor señala que dicha segunda parte «queda mucho más cerca del dominio de lo que hoy se considera Antropología estrictamente» (1985b: 27), en especial los apartados cinco y seis, donde Kant se centra en las cuestiones del carácter (ya sea éste natural, propio del sexo, de los pueblos, las razas o el género humano en su conjunto), adoptando una neta perspectiva eurocéntrica. Caro Baroja afirma entonces que el programa kantiano sigue siendo válido, a pesar de que las caracterizaciones nacionales esbozadas por el filósofo regiomontano en esa sede puedan considerarse ya superadas e insuficientes. De hecho, el posible cariz estereotípico de dichas pinceladas caracteriales es admitido por el propio Kant, que llama la atención sobre el cariz etnocéntrico de los mecanismos de identificación identitaria y advierte respecto a los consiguientes peligros del sociocentrismo y la xenofobia. A ello se refiere Caro Baroja al subrayar el «origen artificial del 'carácter'»(1985b: 28) y la necesidad de estudiar históricamente los procesos conscientes e inconscientes de asunción caracterial por parte de las colectividades, «porque la experiencia indica que, en nuestra época, ha dado resultados preocupadores o pavorosos, con el triunfo de los

\footnotetext{
${ }^{2}$ Según la concepción kantiana, la didáctica antropológica encararía el conocimiento de los aspectos exteriores e interiores del ser humano («das Innere sowohl als das Äußere des Menschen zu erkennen»; Kant 1964: 405), mientras una característica antropológica se centraría más bien en el conocimiento de la dimensión interior a partir de la exterioridad («das Innere des Menschen aus dem Äußere zu erkennen»; op.cit.: 623), ya sea ésta física o comportamental.
} 


\section{Tropelías. Revista de Teoría de la Literatura y Literatura Comparada, 22 (2014) \\ Meditar a contrapelo: carácter y nación en la antropología histórica de Julio Caro Baroja}

nacionalismos de distinto tipo» (ibíd.). De esta forma, observamos cómo la necesidad de indagar en los nudos teóricos planteados por el binomio raza/carácter aparece, al trasluz de la influencia kantiana (Antropología física vs. Antropología pragmática), como el verdadero núcleo del proyecto investigador del antropólogo vasco según su propia confesión. La incómoda presencia de la idea de nación (objeto más histórico que antropológico) no constituye sino el corolario, la piedra de toque que estará siempre por detrás de la posible conformación y aplicación políticamente interesadas de ambos miembros de la pareja raza/carácter. Lo teórico y lo científico dejan paso entonces a lo vivido, al contexto histórico español y europeo en general, así como a las vicisitudes personales experimentadas por el propio Caro Baroja. De ello puede dar muestra un somero análisis de algunos aspectos presentes en su vasta obra.

En realidad, las apuestas subyacentes a dicha obra pueden leerse tomando como punto de partida las dos parejas fundamentales en toda discusión acerca de los mecanismos humanos de identidad e identificación; es decir, por una parte, la difícil convivencia entre permanencia y transformación; por la otra, las dificultades a la hora de articular los componentes humanos individuales y los colectivos. En ambos casos, el concepto de identidad aparecería como necesario trasfondo de la discusión. Respecto a la primera dualidad, hay quien considera que «nada excita tanto el interés de Caro Baroja como esta complicada interacción entre cambio y continuidad» (Grenwwod 1989: 16). De hecho, no es casual que uno de los caballos de batalla de nuestro autor en sus críticas a la tradición antropológica del siglo XIX (con Gustav F. Klemm y Edward B. Tylor a la cabeza) fuera su rechazo de la teoría de los atavismos o survivals, con su consiguiente división entre una mentalidad civilizada (moderna) y un pensamiento propio de pueblos y clases sin historia cuyos restos pervivirían en ciertos segmentos del mundo desarrollado (fundamentalmente, el campesinado). Frente a esta concepción, el autor español reivindicó siempre la complejidad de la dimensión temporal de las sociedades y el reduccionismo subyacente a la pareja sincronía/diacronía. En lo tocante a las complejas relaciones entre la dimensión individual y la colectiva propias de los seres humanos, puede decirse que la misma constituye sin duda una de las preocupaciones más presentes en la obra de Caro Baroja, como veremos a continuación, a propósito de la noción de carácter, a caballo de las inquietudes propias de la Psicología, la Sociología, la Antropología y la Historia. En palabras del propio autor, pronunciadas ya en sus últimos años, «la absorción de lo que desde fuera se ofrece al individuo es el gran problema que tenemos en la antropología» (1985a: 238).

En lo que sigue, y con el objeto de trazar una evolución esclarecedora de las soluciones aportadas por nuestro autor a las cuestiones de la identidad individual y colectiva a través de las nociones de carácter y nación, llevaremos a cabo un breve recorrido por algunos hitos de la extensa obra de Caro Baroja $^{3}$. A tal efecto, estableceremos una tripartición a un tiempo cronológica y temática: si en las obras de los años 40 y 50 veremos predominar las inquietudes en torno a la llamada Etnopsicología, las décadas de 1960-1970 pueden considerarse aquellas en las que Julio Caro llega a adquirir una voz propia, a través de sus estudios caracteriales sobre las minorías étnicas y religiosas y de sus ataques a

\footnotetext{
${ }^{3}$ Un buen punto de partida para acercarse al elenco de las publicaciones del autor puede hallarse en Carreira (1985 y 1989).
} 
la idea de carácter nacional, mientras a partir de los años 80 y hasta su muerte (acaecida en 1995), Caro Baroja llevó a cabo una labor de recapitulación y reubicación de la propia obra en el seno de la tradición antropológica e historiográfica, además de desarrollar algunos fermentos presentes ya en el proyecto kantiano y directamente emparentados con la noción de carácter.

\section{2. Años 40-50: la refundación de la Etnopsicología}

Los primeros textos antropológicos publicados por Caro Baroja, al menos desde 1929 hasta principios de los años 40, tienen un cariz marcadamente etnológico y etnográfico y se centran en su mayoría en el folklore y las tradiciones vascas. A ellos hay que sumarles algunas reseñas relativas a textos de antropología aparecidos en España o más allá de sus fronteras. En lo que atañe al tema de nuestra intervención, nos referiremos en primer lugar a «La raciología», una recensión del discurso pronunciado por Luis Hoyos Sainz con motivo de su ingreso en la Academia de Ciencias Exactas, Físicas y Naturales, en 1944. El punto de partida de Caro Baroja, la base de su acerada crítica, era precisamente la ambigüedad del concepto de raza en antropología, basado en «la generalización superflua» y «la arbitrariedad más completa» (1944: 266), y las endebles bases metodológicas de la Etnopsicología de base nacional. Se recalcaba además el peligroso uso político de las cuestiones raciales, llevado a cabo por «especialistas de una nacionalidad u otra» cuyo trabajo teórico habría propiciado «actitudes extremas en la vida pública» (ibíd.), una expresión más bien eufemística si tenemos en cuenta el año de aparición de la reseña y la convulsa situación europea del momento ${ }^{4}$. Algunos años más tarde, en 1951, aparecerá «Sobre psicología étnica», donde se lleva a cabo una crítica frontal de la disciplina y se ponen las bases de la propuesta metodológica del propio autor. El blanco de los dardos barojianos es sin duda la nutrida literatura histórico-antropológica en torno a los caracteres nacionales entendidos como bloques, más allá de distingos entre clases, sexos, comportamientos conscientes o inconscientes, periodizaciones, etc. Caro Baroja ve en las burguesías nacionales surgidas de la modernización el origen de semejantes enfoques, basados en una injustificada reificación del concepto de nación tendente a ignorar las complejas situaciones étnicas preexistentes en la geografía europea. Por su parte, nuestro autor afirma que un análisis histórico de dichas situaciones permitiría constatar que «las nociones sociológicas, históricas, etc., que hacen juzgar a la nación como forma primordial, deben ser consideradas desde un punto de vista precavido y distinto por nosotros» (1990.: 176). En efecto, frente a ese tipo de estudios basados en el determinismo ${ }^{5}$, el nacionalismo y la generalización abusiva, Caro Baroja aboga por una psicología étnica de base

\footnotetext{
${ }^{4}$ La misma insistencia en el carácter nocivo de la antropología racista está presente en otro trabajo casi coetáneo titulado «Sobre ideas raciales en España» (1956), donde se rastrean aspectos como el del ideal nobiliario castellano de la pureza de sangre o el del goticismo español, a la vez que se condena cualquier racismo y su tendencia a convertirse en «una monstruosidad descomunal» (1990: 168). En dicho ensayo pueden observarse ya los orígenes de los trabajos dedicados por el autor en los años 60 y 70 a las minorías étnicas y religiosas en España.

${ }^{5}$ Consideraciones muy interesantes en torno a la tradición del determinismo geográfico y climático de raigambre hipocrática (una de las bases de la teoría de los caracteres nacionales) pueden hallarse en el trabajo, también de 1951, titulado «Sobre los conceptos de región y comarca», donde se llama la atención sobre lo inadecuado de la rígida oposición entre naturaleza y cultura y sobre la importancia de detectar aspectos culturales en aspectos pretendidamente naturales de la esfera humana y material (1990: 307-318).
} 


\section{Tropelías. Revista de Teoría de la Literatura y Literatura Comparada, 22 (2014) Meditar a contrapelo: carácter y nación en la antropología histórica de Julio Caro Baroja} 161

casuística (es decir, histórica) que parta «del estudio de personas y no de ideas, de las emociones, deseos y pasiones de tales personas, tanto como de sus pensamientos y actuaciones más aparatosas» (op.cit.: 175). En otras palabras, un análisis de la imbricación entre lo colectivo y lo individual que ponga en relación «una serie grande de estados de conciencia con el medio social» (op.cit.: 177) ${ }^{6}$. No es casual que la antropología kantiana vuelva a aparecer como modelo de dicha propuesta investigadora, con la idea de carácter utilizada por Kant, a juicio de Caro Baroja, «en un sentido restringido que no voy a discutir ahora, pero de todas formas laudable» (op.cit.: 171). Los objetivos del proyecto barojiano quedarían resumidos entonces en el estudio de «los tipos de personas más características de una etnia frente a las vecinas» (op.cit.: 177), el análisis de los estados de conciencia más comunes en esos diferentes tipos de personas y la determinación de los factores que «pueden considerarse como de influencia decisiva sobre la formación de la personalidad» (ibíd.). De esta forma, la perspectiva caracterial aparece ya de forma clara y desde fecha temprana como el fulcro del proyecto antropológico de Julio Caro Baroja.

Un paso más en dicho proyecto puede considerarse su aplicación concreta a la situación española. De 1954 es el trabajo titulado «El sociocentrismo de los pueblos españoles», donde, a partir de la noción de etnocentrismo (rebautizado para la ocasión como sociocentrismo) en cuanto constante antropológica, se ensaya una teoría acerca de la imbricación de las diferentes identidades coexistentes en el individuo y de los fenómenos de saliencia asociados a dicha coexistencia. En sus interesantes páginas asistimos a un nuevo ataque contra la posición privilegiada de la idea de nación (España, en este caso) como base de la identidad social de los individuos, identidad distribuida en un semicírculo de radio creciente desde el barrio hasta la susodicha nación, pasando por los espacios intermedios del pueblo, la comarca y la región. Para ello, Caro Baroja opone un criterio de homología, en virtud del cual «el hombre establece un nexo entre su modo de ser y el de los demás, de manera cada vez más amplia» (1990: 279), a un criterio de diferenciación, sobre cuya base los individuos establecen una «separación más o menos radical, pero en general bastante acusada, entre su manera de ser, socialmente (y aun desde otros puntos de vista), y la de diferentes seres humanos» (op.cit.: 280). Si la tendencia a la homología se halla en la base de toda la literatura sobre el carácter nacional español (asociada de nuevo por Caro Baroja a las clases medias intelectuales y burguesas), origen de un «patrioterismo»o «patriotismo hostil» españolista execrado por el autor, el criterio de la diferenciación puede rastrearse en «los sistemas de realce que poseen los antiguos reinos y estados que hoy quedan dentro de ellas [las naciones]» (op.cit.: 285). No obstante, frente a dichas dimensiones (la estatal, nacional o regional), Caro Baroja hace hincapié en la prelación histórica y social de las identidades rurales y urbanas (aldea, comarca, barrio...), precisamente aquellas que constituyen la base de sus estudios etnológicos durante esos años. Para visualizar dicha prioridad, nuestro autor se sirve de un diagrama cronológico en el que la nación aparece como el último y más endeble de los círculos identitarios del contexto español (no

\footnotetext{
${ }^{6}$ En un ensayo posterior, titulado «La investigación histórica y los métodos de la etnología (Morfología y funcionalismo)» (1955), Caro Baroja emparenta la literatura del siglo XVII con una «inquietud psicológica» dominante y la contrapone a las «inquietudes sociales» propias de la centuria siguiente. En la posterior imagen que ve a Racine y Molière por un lado y a Voltaire y Rousseau por el otro no es difícil rastrear la dualidad carácter individual / carácter nacional (1990: 37).
} 
anterior en ningún caso al siglo XVI), mientras las identidades regionales previas no irían más allá de la Baja Edad Media, frente a las identificaciones de las zonas rurales y los núcleos urbanos, que se remontarían en algunos casos nada menos que hasta el siglo XI antes de Cristo. De su diagrama deduce el autor que la mayor antigüedad «implica hasta cierto punto si no más fuerza coercitiva en un momento dado, si más plasticidad y fuerza propia permanente» (op.cit.: 288), expresando a las claras su desconfianza ante los proyectos políticos de base nacional. No parece descabellado ver en la retórica nacionalista del franquismo el verdadero blanco de esos dardos envenenados.

Sin abandonar el contexto español como escenario privilegiado de sus investigaciones, fiel a su proyecto de psicología étnica de base caracterial más interesado en las personas y los estados de conciencia individuales (y en sus relaciones con la dimensión social y colectiva) que en las ideas, Caro Baroja emprenderá en los años 60 y 70 una serie de trabajos cuyo hilo conductor será el concepto de carácter entendido como arquetipo o modelo de identificación. Descartada la idea de nación como fundamento definitorio de lo caracterial, nuestro autor deberá recurrir a otros posibles vectores, entre los que merece la pena destacar lo étnico, lo literario o lo profesional.

\section{3. Los años 60-70: cuestión de carácter}

De 1961 es la monumental obra en tres tomos Los judios en la España moderna y contemporánea, donde Caro Baroja traza una abigarrada historia del antisemitismo en España basada en la deconstrucción y reconstrucción de los lugares comunes argumentativos (icónicos y literarios) subyacentes a dicha actitud etnocéntrica (deicidio, usura, soberbia e inteligencia particular, diferencia física, aspecto desagradable, etc...). No es casual que en dicho análisis desempeñe un papel central (especialmente en el primer volumen del trabajo) la existencia de un «carácter judío» (a él se le dedica el cuarto capítulo del primer tomo) en cuanto constructo histórico elaborado (en España y en otras partes) por el pensamiento antihebreo a base de «simplificaciones, selecciones y tipificaciones» (1961: 98) que quedarán objetivadas en el refranero, las representaciones plásticas, el teatro, la literatura o las descripciones psicológicas. Entre las múltiples fuentes utilizadas por el autor destacan no sólo la producción ficcional (popular o culta) sino una nutrida documentación inquisitorial, así como ejemplos de literatura jurídica o teológica, según el modelo kantiano de una antropología de los pueblos históricos antes mencionado y que tantos frutos había de dar en la obra barojiana. Respecto al acopio de fuentes literarias y su directa relación con el análisis caracterial, merece la pena mencionar también aquí el artículo titulado «Menandro y los campesinos del Mediterráneo», publicado en 1966, si bien su redacción se remonta a 1963 (al hilo del descubrimiento en 1957 del texto casi íntegro de la comedia menandrina El díscolo). Una vez más, el punto de partida es la relación de cambio y continuidad entre mundo clásico, moderno y contemporáneo a través de los lugares comunes y estereotipos fraguados en el seno de la ciencia, la filosofía o, como en este caso, la literatura. Nuestro autor aboga por un uso antropológico, sociológico e histórico de las obras literarias, censurando la actitud puramente textualista de cierta crítica filológica que, a su juicio, parece saber «más de palabras y cosas que de hombres y pasiones» (1966: 40). Los aspectos resaltados por Caro Baroja, centrados en las 
dimensiones comportamentales y psicológicas de los personajes, tienen que ver en su mayor parte con los tópicos sobre la pobreza y la honra o con la oposición estereotipada entre medio rural y medio urbano. En todos lo casos, el autor hace especial hincapié en «la perennidad de ciertos caracteres» (op.cit.: 60). De esta forma, la literatura aparece como elemento indispensable a la hora de analizar históricamente las relaciones entre individuo y colectividad, entre vida y sociedad, permanencia y cambio. En otras palabras, «desaparecen las religiones y las creencias, los gustos cambian: pero los valores sociales, los lugares comunes acuñados hace siglos y siglos se afianzan» (op.cit.: 61).

La importancia del elemento biográfico y de los aspectos psicológicos en el análisis antropológico e histórico, así como el interés por los grupos marginales y las fuentes inquisitoriales y literarias (rasgos ambos bien visibles en los textos de la primera mitad de los años 60), están en la base de Vidas mágicas e Inquisición, otro extenso trabajo en dos tomos aparecido en 1967. Ya desde el prólogo al primero de los volúmenes, la noción de personalidad y el estudio de los estados de conciencia y de los aspectos pasionales (no racionalizados), aplicados en este caso al estudio de la Magia y su contexto ideológico y social en la historia de España, aparecen como el trazo de unión entre lo individual y lo colectivo. Una vez más, Caro Baroja critica las posiciones textualistas de base filológica, en esta ocasión el estudio de los tópicos retóricos llevado a cabo por Ernst Robert Curtius en su célebre Europäische Literatur und lateinisches Mittelalter (1948) y su desatención por los aspectos contextuales ${ }^{7}$. A través de la noción de arquetipo o modelo aplicada a la tipificación de personalidades, el autor esboza toda una teoría sobre las relaciones entre literatura y vida, mientras va rastreando en textos ficcionales, folklóricos, legales o religiosos (de los legajos inquisitoriales al Quijote) las huellas de esas personalidades o vidas mágicas donde se entremezclan los seres humanos de carne y hueso con los estereotipos sociales, profesionales o caracteriales. Es el caso de figuras como la hechicera celestinesca, el médico judío entre nigromante y envenenador o la quiromante de etnia gitana, entidades sujetas a una lógica circular que ve continuamente imbricados los textos y los contextos. Así, en ocasiones nos hallamos ante «un arquetipo que domina sobre la Literatura y la Sociología, ni más ni menos», pero también «sobre la personalidad individual» (1967: 44). En otras palabras, «del concepto se pasa al personaje literario: del personaje literario a la realidad» (op.cit.: 164).

Esa misma lógica entre lo arquetípico y lo biográfico, enhebrada siempre a través de la noción de carácter (en sus múltiples sentidos, de lo ético a lo retórico, de lo literario a lo psicológico), constituye también el punto de partida de El señor inquisidor y otras vidas por oficio (1968), una breve colección de biografías apoyadas en la metodología ensayada por Caro Baroja en sus trabajos de la primera mitad de los años 60, a la que se añade el elemento vertebrador de la profesión o el oficio como base de la generación de caracteres prototípicos. En el prólogo al volumen, titulado de forma muy significativa «Sobre el arte de la biografía», se vuelve a aludir de forma velada a la polémica con

\footnotetext{
${ }^{7}$ En el extenso artículo titulado «Reflexiones sobre Folklore», publicado también en 1967, se vuelve a aludir al trabajo de Curtius, cuyos límites textualistas se describen de nuevo en los mismos términos pero que esta vez es reconocido como «una contribución importantísima para el estudio de la tradición literaria europea» (1979: 52).
} 
Curtius al hacer hincapié en la importancia de la Retórica («una disciplina mucho más profunda de lo que se ha dicho en tiempos modernos»; 1968: 12) como saber con un gran peso en la formación de esos tipos ideales no tanto o no sólo en el plano textual como también en el contextual ${ }^{8}$. Más adelante, en el capítulo dedicado a la figura de Rodrigo Alemán como encarnación del mito del artífice (el prototipo de Dédalo e Ícaro), se vuelve a insistir sobre este punto al afirmar que «antes y después de que exista Fulano o Zutano, se da la idea de unos hombres que se comportan como él se ha comportado o se dice que se ha comportado» (op.cit.: 169). Esta noción de modelo o arquetipo caracterial, tan cercana a la manejada por la Tematología en el seno de los estudios literarios (los llamados tipos), será desarrollada ulteriormente por nuestro autor en algunos otros ensayos de los años 70. Es el caso de «Arquetipos y modelos en relación con la historia de la brujería» (1974), «Sobre la formación y uso de arquetipos en Historia, Literatura y Folklore» (1979) y, sobre todo, del denso trabajo Las formas complejas de la vida religiosa (religión, sociedad y carácter en la España de los siglos XVI y XVII) (1978), que el propio autor llegó a considerar, de entre todos los suyos, «el que mejor está escrito» (1985a: 42). En efecto, en esta obra la elaboración teórica de la noción de carácter aparece ya concluida y su aplicación práctica perfectamente lograda. La influencia de la retórica y la poética como disciplinas aplicables al estudio de la historia aparece explicitada ya desde el prólogo, donde se alude a la metáfora del gran teatro del mundo como imagen útil a la hora de comprender ciertas realidades sociales y se afirma que el objetivo de esas páginas era llevar a cabo «un padrón, un recuento de lo que en términos teatrales se denomina 'dramatis personae': un poco al estilo de la comedia nueva, ética, la de Menandro, en que aparecen caracteres, no individuos determinados» (1978: 17). Además, las implicaciones éticas, poéticas, retóricas, filosóficas, historiográficas y psicológicas de la idea de carácter aparecen plasmadas en los nombres de Herodoto, Platón, Teofrasto o La Bruyère, traídos a colación en diferentes lugares del texto. Por otra parte, el contrapunto de la noción de carácter (ya sea literario, retórico, profesional o social) como herramienta metodológica para poder analizar la dialéctica entre cambio y permanencia, entre individuo y colectividad, es sin duda la idea de carácter nacional, llamada en causa también en repetidas ocasiones a lo largo de Las formas complejas de la vida religiosa, como veremos más adelante, siempre con una connotación negativa. En realidad, el interés de Caro Baroja por dicho concepto había empezado ya muchos años antes, como vimos al hilo de sus estudios de los años 50 centrados en la reelaboración de la Etnopsicología y en la necesidad de afrontar un análisis de los lugares comunes de cariz satírico y moral derivados del sociocentrismo o etnocentrismo de toda sociedad o grupo humano, incluida la nación como producto propio de la

\footnotetext{
${ }^{8}$ En el breve artículo «De la anécdota al modelo histórico» (1970), en polémica con la aplicación de esquemas propios de las ciencias naturales y matemáticas a las disciplinas sociales, se vuelve a insistir en la importancia de los caracteres retóricos a propósito del arquetipo del joven ambicioso e intrigante y se lanza un significativo interrogante: «¿Por qué Aristóteles hizo la descripción de la juventud en su «Retórica» o arte de persuadir y no en otro tratado?» (1970: 66-67). Ética, Poética, Retórica, Historia y nación vuelven así a confluir a través de la noción de carácter, según una concepción muy proficua y bien presente hoy día en las indagaciones del imagólogo neerlandés Joep Leerssen sobre el inescindible vínculo entre las ideas occidentales de carácter y nación (2000, 2006 y 2007). Desde el punto de vista propio de la historia de la literatura y de la cultura, una introducción a las raíces clásicas de la noción de carácter y su evolución en diferentes géneros literarios (o no), puede hallarse en Smeed (1985) y Van Delft (1993).
} 


\section{Tropelías. Revista de Teoría de la Literatura y Literatura Comparada, 22 (2014) \\ Meditar a contrapelo: carácter y nación en la antropología histórica de Julio Caro Baroja}

modernidad. Una inquietud y un proyecto que no cesaron de interesar a nuestro autor en los años sucesivos.

En efecto, en un extenso artículo titulado «Reflexiones sobre el Folclore» (1967), una introducción a la Antropología y a la Etnología a través del complejo concepto de Pueblo, se vuelve sobre la idea de sociocentrismo y sobre los mecanismos de estereotipación de rasgos propios de los exogrupos en una amplia escala que va del poblado o la comarca hasta la región o la nación. Al referirse a las esquematizaciones de base nacional, Caro Baroja menciona el caso español, en especial el período a caballo entre finales del siglo XIX y principios del XX, con autores como Ángel Ganivet o Rafael Altamira, responsables, entre muchos otros, de lo que nuestro autor considera «una especie de desenfreno ensayístico sólo comparable al que en época reciente también se ha dado en Norteamérica» (1979: 79), en clara alusión a las posiciones teóricas de antropólogos como Margaret Mead, Geoffrey Gorer o Ruth Benedict, que a partir de los años 50 de la pasada centuria desempolvaron el vetusto concepto de carácter nacional y trataron de revestirlo de una pátina científica. Para Caro Baroja, se trataba de especulaciones peligrosas «en manos de técnicos y tecnócratas que tras un supuesto aparato científico nos pueden querer imponer ciertas ideas y aun dogmas contrarios a la libertad del individuo y aun a la de grandes grupos de hombres y mujeres» (ibíd.). Idéntica actitud respecto a la noción de carácter nacional, basada en la desconfianza e incluso el desprecio hacia esas tentativas, puede rastrearse en «Modos de vivir hispánicos», un texto casi coetáneo (se publicó en 1968) donde se analiza un curioso libro de Fray Benito de Peñalosa y Mondragón, Libro de las cinco excelencias del español que despueblan a España para su mayor potencia y dilatación, aparecido en Pamplona en 1629. En los primeros párrafos del texto, nuestro autor llama la atención sobre lo ambiguo del título de su intervención, que «suena a un género de ensayismo, del que puede estar más en boga, pero que no es de mi gusto», por lo que se apresura a subrayar el cariz relativista de sus reflexiones: «voy a hablar de «modos de vivir que se atribuyen a los españoles» y de los que éstos se atribuyen a sí mismos» (1998: 149). A este respecto, son muy significativas las conclusiones obtenidas por nuestro autor al hilo del discurso de Peñalosa, que creía ver en el concepto griego (y, en especial, hipocrático y aristotélico) de hybris (desequilibrio, orgullo y desmesura) el núcleo definitorio del carácter español ${ }^{9}$. Señala Caro Baroja que la propia idea de españolidad vigente en un período determinado en ciertas clases o grupos (la autoimagen social) está en la base de determinados comportamientos que son percibidos por los miembros de ese grupo como propios de esa idea en cuanto se ajustan a un estereotipo social previo. En otras palabras (que vienen a disolver la creencia en un carácter nacional hispano), «el español caracterizado por el Padre Peñalosa y por otros de manera parecida es producto no de un grupo étnico particular (vasco, catalán, andaluz o castellano), ni de una tierra simplemente considerada, sino de un

\footnotetext{
${ }^{9}$ El uso de esquemas y conceptos retóricos y literarios (empezando por el de carácter) fue también, como hemos señalado, uno de los rasgos definitorios de la obra de Caro Baroja. No en vano, el autor señala que el libro de Peñalosa «nos coloca ante un método de investigación» y habla de «un resultado originalísimo [...] al que creo no han llegado autores más modernos» (1998: 160 y 161). La concepción trágica (en sentido literario) de la historia presente en autores como Herodoto fue subrayada y compartida por Caro Baroja en repetidas ocasiones cuyo cumplido análisis excede por desgracia el aliento de estas páginas.
} 
Estado, o si se quiere, de un sistema de gobierno» (1998: 161). El blanco de semejante ataque, como ya sucediera en los trabajos barojianos de los años 50, vuelven a ser las posiciones esencialistas del nacionalismo español tendentes a retrotraer la existencia de la nación española a una fase casi natural y primigenia. Muy al contrario, afirma Caro Baroja, «lo español es algo limitadísimo aun dentro de España, por muchos esfuerzos que hagan los mismos que pretenden definirlo, buscando antecedentes en la Edad Antigua, en textos griegos, romanos, etc.» (ibíd.).

Contra semejantes posiciones sólo queda el recurso a la historia, parece pensar nuestro autor. Consecuencia de esa actitud es su celebérrimo trabajo «El mito del carácter nacional y su formación con respecto a España», que daba título al volumen El mito del carácter nacional: meditaciones a contrapelo, aparecido dos años después (en 1970) y compuesto por algunos textos breves que flanqueaban al apenas mencionado, algo más extenso. En dicho ensayo, Caro Baroja no hace sino sistematizar las ideas sobre el concepto de carácter nacional desperdigadas a lo largo de todas las obras examinadas hasta ahora y engarzarlas en el cuerpo de un análisis cronológico referido al caso español. Por sus páginas desfilan, de forma inevitable, de Tácito a Ammiano Marcelino, de Scaligero a Cervantes, Gracián o Peñalosa, del padre Feijóo a Masdeu o Galdós, de Mallada a Valera. El irritado punto de partida de Caro Baroja vuelven a ser las teorías de Margaret Mead, acusadas de querer nacionalizar la antropología y consideradas, al igual que toda la tradición de pensamiento en torno a los caracteres nacionales, poco científicas y más bien peligrosas. Para el autor, «todo lo que sea hablar de 'carácter nacional' es una actividad mítica; [...] el que habla o charla se ajusta a una tradición, más o menos elaborada, sin base que pueda apoyarse en hechos científicamente observados y observables» (1970: 72). Esa tradición, referida en este caso al contexto español, es precisamente la que se va desgranando en las interesantes páginas del ensayo de Caro Baroja, sin que su autor pueda nunca dejar de resaltar lo variable y objetivamente injustificado de dichas caracterizaciones, pero sin que pueda tampoco negar su importancia histórica en cuanto patrones de identificación con consecuencias concretas y materiales. Como vimos con anterioridad, el destinatario principal de sus críticas es la larvada concepción nacionalista propia de la Etnopsicología surgida en Europa en el siglo XIX, asî como sus derroteros políticos. En efecto, las consideraciones finales están dedicadas a las consecuencias que el proceso analizado a lo largo del ensayo tuvo en el contexto español contemporáneo. En esas últimas páginas, el autor afirma, en alusión a las llamadas dos Españas, que la reificación de cierta concepción de lo que debería ser propio del carácter español acabó convirtiéndose en una contraposición irreductible y «llegó a lucha enconada, y entonces se definió, precisamente, qué cosa era ser ‘mal' o ‘buen' español, y se hizo la guerra civil» (1970: 112).

Aunque «El mito del carácter nacional...» es sin duda el punto más alto de la reflexión barojiana respecto a dicha cuestión, su autor no dejó de ocuparse de la misma en aquellos años del franquismo tardío y en los primeros tiempos de la transición democrática. El revuelo y la relativa transcendencia pública de su ensayo de 1970 pueden deducirse de la publicación de «Sobre caracterizaciones nacionales y regionales» en la revista Triunfo, en 1972, donde se vuelve a insistir en el sociocentrismo (denominado ahora «lejanía peyorativa») y en los procesos de estereotipación étnica y nacional, sin 


\section{Tropelías. Revista de Teoría de la Literatura y Literatura Comparada, 22 (2014) \\ Meditar a contrapelo: carácter y nación en la antropología histórica de Julio Caro Baroja}

perder ocasión de fustigar de nuevo a la antropología norteamericana centrada en el estudio del carácter nacional ${ }^{10}$. Quizá el aspecto más interesante de este breve texto sea para nosotros la insistencia en Castilla y en la literatura castellana como los verdaderos orígenes del acervo de lugares comunes peyorativos en torno a los pueblos europeos y peninsulares (italianos, franceses, ingleses, portugueses, catalanes, andaluces o vascos) que circularon por España durante siglos ${ }^{11}$. De forma muy significativa, Caro Baroja añade: «Sobre esta base se funda la idea de Unidad. ¡Qué cosa más vieja y más moderna a la par! ¡Qué pobre y qué peligrosa!» (1972: 82). Semejante inquina respecto al moderno concepto de Estado-nación centralizado (y su plasmación en el contexto de la Península Ibérica) puede considerarse como el verdadero motor del intento barojiano por desenmascarar los mecanismos de formación de las autoimágenes y heteroimágenes que cristalizarán en la teoría de los caracteres nacionales a partir del Renacimiento, aunque a su formación contribuyeran materiales de derribo provenientes de la Antiguiedad grecolatina (desde la tradición galénica de los humores hasta la creencia hipocrática en el determinismo climático, pasando por la teoría ética, poética y retórica de los caracteres individuales y colectivos). Confirmación directa de lo dicho puede hallarse en el ya mencionado Las formas complejas de la vida religiosa (1978), donde Caro Baroja no sólo considera la cuestión de los caracteres nacionales, «un asunto que llega a ser irritante» (1978: 322), sino que, en las últimas páginas, consiente en desvelar el origen de su interés por las minorías étnicas, los grupos oprimidos o las personalidades marginales. Relata el autor que, interrogado a ese propósito por el filósofo e historiador Michel de Certeau, su respuesta le llevó a exponer dos motivos muy arraigados en su interior: en primer lugar, su contacto prolongado con el medio rural vasco y los problemas específicos del mismo; en segundo lugar, «otra raíz que ahora queda más vigorosa» y que el autor define como «mi reacción constante, mantenida, contra los tópicos de la retórica política unitaria española que se dicen extraídos de la Historia misma: Historia de España en primer término» (1978: 601). Una vez concluido el franquismo centralista e iniciados los tiempos revueltos de la transición hacia el Estado de las Autonomías, parecía llegada la oportunidad de abandonar ese interés de décadas en beneficio de otras posibles orientaciones. Sin embargo, las cosas no iban a resultar tan sencillas.

\footnotetext{
${ }^{10}$ En «Sobre la formación y uso de arquetipos en Historia, Literatura y Folklore» (1979), el trabajo de Caro Baroja donde mejor se sistematiza su teoría del Arquetipo y del Mito a partir de la noción de estereotipia, no podía faltar un capítulo titulado «Caracteres étnicos y nacionales como arquetipos». En esas páginas, el autor traza una incipiente distinción entre los fenómenos de caracterización individual, moral y social, ligados al mecanismo de la generalización, que hace que «las cosas sean más inteligibles colocadas en series ordenadas», y la caracterización de base étnica y nacional, basada en «una tendencia a la pereza mental, [...] por la ley del mínimo esfuerzo» (1979: 162-163). En esas páginas, volvemos a toparnos con la mención despectiva y crítica respecto a la antropología norteamericana del carácter nacional y su falta de cientificidad (ibíd.).

${ }^{11}$ En el ensayo titulado «De nuevo sobre ‘caracteres étnicos': lo vasco y vizcaíno y ciertos tópicos literarios» (1974), un airado Caro Baroja volvía a cargar contra la literatura castellana (con Lope, Cervantes, Quevedo o Gracián a la cabeza) y su mal celado etnocentrismo, cristalizado en una batería de tópicos peyorativos respecto a los naturales de otras partes de la Península. «Acaso no haya tema más miserable en las letras españolas» (1974: 102), sentenciará el autor con rabia poco disimulada.
} 


\section{4. Los años 80-90: entre el presente y el pasado}

A este respecto, son muy significativas las palabras incluidas en el «Prólogo» al volumen Ensayos sobre la cultura popular española, aparecido en 1979 y que recogía una mezcla de textos inéditos con otros ya publicados anteriormente. A propósito de la idea de «cultura popular española» que da título al libro, Caro Baroja no duda en defender su existencia, si bien se apresura a dejar clara su desconfianza ante la idea de «una unidad cultural absoluta de los pueblos de la península ibérica» (1979a: 7) y hace hincapié en su dilatada e importante contribución científica a la hora de rebatir dicha idea. El motivo de semejante disclaimer hay que buscarlo sin duda en los debates en torno a la cuestión nacional que se produjeron en la España de la Transición, con el resurgimiento (tras el paréntesis represivo del franquismo) de los llamados nacionalismos periféricos (en especial el vasco, el gallego y el catalán) y el descrédito momentáneo del nacionalismo español de cuño reaccionario y centralizador. La salvedad expresada por Caro Baroja trataba así de adelantarse a las objeciones de quienes, «a causa del abuso con que se han utilizado durante largos años palabras tales como España, español, hispánico y derivados cuales los de Hispanidad y hasta Españolidad y españolear», pudieran adivinar «secretas intenciones políticas en el que hable de algo que es 'español'» (1979a: 7).

En esa nueva situación política, un más bien hastiado Caro Baroja se verá inmerso en discusiones de cuño político presentista, especialmente en torno a la delicada situación social vivida en Euskadi en aquellos años. La ligazón emocional de nuestro autor con el País Vasco es, quizá, el rasgo más evidente de su vida y de su obra, por lo que los textos de la primera mitad de los años 80 incluidos en El laberinto vasco (1984) o en Escritos combativos (1985) tienen un cariz especialmente sentido. En lo que atañe a nuestro discurso, no disponemos de espacio suficiente para llevar a cabo un análisis siquiera somero de los temas y discusiones presentes en textos como «Tópicos, equívocos, falsedades» (1980), «Sobre la identidad vasca (ensayo de identidad dinámica)» (1984), «Reflexiones sobre el populismo» (1984), «Sobre la violencia actual y sus 'causas'» (1984) o «El espacio 'natural' de los autonómicos» (1984), entre otros. Bástenos decir que las argumentaciones de Caro Baroja vuelven a recurrir a su consideración de los caracteres nacionales como estereotipos dañinos transmitidos por la literatura y a hacer hincapié en el cariz mítico del populismo nacionalista (sea cual sea la nación que lo sustente) y de las teorías etnopsicológicas o en la pasión etnocéntrica como rasgo propio de toda colectividad. En el fondo, todos esos escritos transmiten la idea de un autor desengañado, de un hombre de otro tiempo cansado de repetir los mismos argumentos ante situaciones sólo aparentemente nuevas. Una vez más, la sempiterna repetición cíclica de esquemas y tramas.

En realidad, más allá de los debates políticos, en la segunda mitad de los años 80, la actividad científica de Caro Baroja siguió regalándonos obras de gran interés también en lo que respecta al tema que nos ocupa. Su posición en torno a la cuestión de los caracteres étnicos y nacionales no variará un ápice en textos como «Tópico literario y caracterización antropológica: caracteres nacionales», publicado en Revista de Occidente en 1986, o en el prólogo antepuesto a La selva de los tópicos (un libro de Emilio Temprano publicado en 1988 y dedicado a los estereotipos existentes acerca de las regiones españolas), donde un anciano Caro Baroja declara haber aceptado prologar el libro por el 
interés que tuvo en el pasado respecto al tema, si bien, añade, «ahora he de decir que me produce tristeza» (1988c: 11). Esa tristeza no le impidió, por lo demás, proseguir en su proyecto histórico y antropológico de raigambre kantiana, bien visible en varias de sus últimas obras, resultado casi todas ellas de la publicación de materiales elaborados por nuestro autor para diferentes cursos impartidos a lo largo de los años 80 en el Consejo Superior de Investigaciones Científicas (CSIC) de Madrid. El rasgo en común de todos estos trabajos es el intento de sistematización histórica y teórica del pensamiento antropológico occidental, es decir, de la reflexión en torno al ser humano, más allá de su moderna compartimentación en disciplinas especializadas o asignaturas académicas. Así, en La aurora del pensamiento antropológico. La antropología en los clásicos griegos y latinos (1983) la noción griega de carácter está muy presente en el capítulo dedicado a la etnografía de tradición hipocrática o en las páginas centradas en la teoría de los climas y su importancia en el pensamiento occidental posterior, sin olvidar la atención prestada a una disciplina fundamental en el mundo clásico y hasta hace poco desatendida como la fisiognómica ${ }^{12}$. La continuación lógica y cronológica de esa obra podemos hallarla en Los fundamentos del pensamiento antropológico moderno (1985), una visión muy personal de la historia de la antropología a partir de finales del siglo XVIII y hasta mediados del siglo $\mathrm{XX}$ que funciona como justificación de la propia obra y como vademecum para quienes deseen ubicar mejor las inquietudes teóricas del autor español.

Al dar inicio al presente trabajo, nos referimos a los dos primeros capítulos de dicha obra, dedicados precisamente a la figura de Kant como numen tutelar del proyecto barojiano. Por su parte, los capítulos III-IX trazan un sucinto recorrido a través de corrientes y autores europeos entre filosofía, antropología y sociología, mientras el capítulo X está dedicado a la antropología norteamericana, con especial énfasis en figuras como Franz Boas o Robert Harry Lowie. En realidad esos capítulos forman un paréntesis entre la presentación de Kant como pionero de un proyecto nunca proseguido (excepto por el propio Julio Caro Baroja, se entiende) y los tres últimos capítulos del volumen, centrados en aspectos de la cultura europea poco conocidos por el mundo anglosajón y, por lo tanto, omitidos en las historias dominantes de la antropología. A decir verdad, esos capítulos finales constituyen una glosa o amplificación de algunos aspectos mencionados o contemplados en la «característica antropológica» kantiana. Más concretamente, el autor se detiene en la escuela folklorista europea del siglo XIX (base de la tan añorada antropología de los pueblos históricos), en una corriente paralela como es la criminología italiana y en las desviaciones antropológico-políticas basadas en el racismo. No es difícil darse cuenta de que el elemento común a todas ellas es precisamente la noción de carácter (y, en segunda instancia, la de nación), como ve con agudeza Caro Baroja al relacionar la literatura costumbrista española con la tradición moralista de Teofrasto a La Bruyère (cf. 1985b: 140-142) o al

\footnotetext{
${ }^{12}$ Uno de los últimos trabajos de Caro Baroja, totalmente construido sobre la noción de carácter, fue precisamente Historia de la fisiognómica. El rostro y el carácter (1985), un fascinante y erudito recorrido por la historia de una disciplina a caballo entre lo empírico y lo mítico desde sus orígenes griegos y su explosión renacentista hasta sus plasmaciones modernas. No olvidemos que Kant dedicó un entero parágrafo a esta disciplina («Von der Physiognomik») en su Anthropologie in pragmatischer Hinsicht, publicada en 1798 (Kant 1964: 638-647). Un excelente panorama de las bases culturales propias del pensamiento antropológico en el mundo antiguo puede hallarse en Sassi (1988).
} 
retrotraer hasta la fisiognómica y la frenología los orígenes de la antropología criminal (op.cit.: 146151). Respecto a la antropología racista, a las objeciones ya examinadas al ocuparnos del concepto de Etnopsicología en Caro Baroja, se suman ahora las andanadas contra el evolucionismo antropológico y el nacionalismo esencialista como verdaderos impulsores del racismo científico y sus derivados políticos (op.cit.: 164-167).

En última instancia, la intención del antropólogo vasco al indagar en los orígenes y en los avatares del pensamiento antropológico antiguo y moderno fue poner de manifiesto la supervivencia de arcaísmos, mitos y actitudes poco objetivas en una tradición antropológica occidental que se pretende neutra y científica. La noción de carácter étnico y su utilización por parte de las diferentes naciones y estados se presentan así a las claras como el origen de lugares comunes y estereotipos cuyos restos se hallan bien interiorizados aún a día de hoy en la opinión pública y son transmitidos por la literatura o los medios de comunicación, así como por franjas enteras de las ciencias sociales, como no dejó de poner de manifiesto nuestro autor, anticipándose así a la necesaria labor de autoanálisis llevada a cabo por los estudios comparatistas de corte imagológico en las últimas décadas. El estudioso neerlandés Joep Leerssen, refiriéndose a la asunción básica de la imagología practicada por Hugo Dyserinck y su escuela a partir de los años 70 del siglo pasado, expresaba hace unos años con claridad el cariz constructivista de los nuevos enfoques, que coincide en buena medida con la actitud epistemológica de Julio Caro Baroja hasta aquí examinada: «images concerning character and identity are not mental representations which are conceived by nations about nations but which, as articulated discursive constructs circulating through societies, are constitutive of national identification patterns» (Leerssen 2007: 23). Como ya afirmamos en otra ocasión, a propósito de la exitosa formulación enunciada en 1951 por Jean-Marie Carré para referirse al objetivo de la imagología, no se trata de estudiar comment nous voyons-nous entre nous, sino de indagar en las condiciones de posibilidad de la oposición entre un nosotros y un ellos y determinar qué papel desempeñan los sistemas simbólicos (incluida la literatura) y los saberes reglados en ese proceso de identidad étnica y nacional que necesita indefectiblemente la alteridad para constituirse (Santos Unamuno 2009: 430). Consideramos que trabajos como los llevados a cabo por Julio Caro Baroja pueden constituir un ejemplo de honestidad intelectual y un acicate para las ciencias humanas y sociales que, como la Literatura Comparada, quieran distinguirse por su espíritu crítico y científico y por su vocación de independencia.

\section{Referencias bibliográficas}

Beller, Manfred y LeERSSEn, Joep (2007): Imagology. The Cultural Construction and Literary Representation of National Characters. A Critical Survey. Amsterdam / Nueva York, Rodopi. CARo Baroja, Julio (1944): «La raciología», Revista Internacional de Sociología, V, abril-junio, pp. 264-268.

- (1961): Los judios en la España moderna y contemporánea. Madrid, Arión, vol. 1. (1966): «Menandro y los campesinos del Mediterráneo», en La ciudad y el campo. Madrid, Alfaguara, pp. 36-62. 
Meditar a contrapelo: carácter y nación en la antropología histórica de Julio Caro Baroja

(1967): Vidas mágicas e Inquisición. Madrid, Taurus, vol. 1.

(1968): El señor inquisidor y otras vidas por oficio. Madrid, Alianza.

(1970): El mito del carácter nacional. Meditaciones a contrapelo. Madrid, Seminarios y Ediciones.

(1972): «Sobre caracterizaciones nacionales y regionales», Triunfo, no 532 (extra), 9 de diciembre, pp. 81-83.

(1974): «De nuevo sobre 'caracteres étnicos': lo vasco y vizcaíno y ciertos tópicos literarios», en De la superstición al ateísmo (Meditaciones antropológicas). Madrid, Taurus, pp. 101-121.

- (1978): Las formas complejas de la vida religiosa. Religión, sociedad y carácter en la España de los siglos XVI y XVII. Madrid, Akal.

- (1979): Ensayos sobre la cultura popular española. Madrid, Dosbe.

(1983): La aurora del pensamiento antropológico. La Antropología en los clásicos griegos y latinos. Madrid, CSIC.

- (1984): El laberinto vasco. San Sebastián, Txertoa.

- (1985a): Disquisiciones antropológicas. Madrid, Istmo.

_ (1985b): Los fundamentos del pensamiento antropológico moderno. Madrid, CSIC.

_ (1985c): Escritos combativos. Madrid, Ediciones Libertarias.

- (1986): «Tópico literario y caracterización antropológica: caracteres nacionales», en Revista de Occidente, $\mathrm{n}^{\circ}$ 56, enero, pp. 91-103.

- (1988a [1987]): Historia de la fisiognómica. El rostro y el carácter. Madrid, Istmo.

— (1988b): «Prólogo», en Emilio Temprano, La selva de los tópicos. Madrid, Mondadori, pp. 1118.

_ (1990 [1957]): Razas, pueblos y linajes. Murcia, Universidad.

— (1998 [1968]): «Modos de vivir hispánicos», en Miscelánea histórica y etnográfica. Compilación Antonio Carreira y Carmen Ortiz. Madrid, CSIC, pp. 146-161.

CARreIRA, Antonio (1985): «Bibliografía de Julio Caro Baroja», en Julio Caro Baroja - Emilio Temprano, Disquisiciones antropológicas. Madrid, Istmo, pp. 455-491.

_ (1989): «Julio Caro Baroja: bibliografía esencial», en AA. VV., Julio Caro Baroja. Premio Nacional de las Letras 1985. Barcelona, Anthropos/Ministerio de Cultura, pp. 134-140.

CARreIRA, Antonio y OrTIZ, Carmen (1998): «Prólogo», en Julio Caro Baroja, Miscelánea histórica y etnográfica. Madrid, CSIC, pp. IX-XIV.

CID, Jesús Antonio (1989): «La literatura oral y popular en la obra de Julio Caro Baroja», en AA. VV., Julio Caro Baroja. Premio Nacional de las Letras 1985. Barcelona, Anthropos/Ministerio de Cultura, pp. 68-88.

GREENWOOD, Davvyd (1989): «Etnicidad, identidad cultural y conflicto social: una visión general del pensamiento de Julio Caro Baroja», en AA. VV., Julio Caro Baroja. Premio Nacional de las Letras 1985. Barcelona, Anthropos/Ministerio de Cultura, pp. 12-33. 
172 Tropelías. Revista de Teoría de la Literatura y Literatura Comparada, 22 (2014)

Enrique Santos Unamuno

KANT, Immanuel (1964): Schriften zur Anthropologie Geschichtsphilosophie Politik und Pädagogik. Frankfurt am Main, Insel Verlag.

LEERSSEN, Joep (2000): «The Rhetoric of National Character: A Programmatic Survey», Poetics Today, 21/2, pp. 267-292.

(2006): National Thought in Europe. A Cultural History, Amsterdam, Amsterdam University Press.

- (2007): «Imagology: History and Method», en Manfred Beller y Joep Leerssen, eds., Imagology. The Cultural Construction and Literary Representation of National Characters. A Critical Survey, Amsterdam/New York, Rodopi, pp. 17-32.

ProietTi, Paolo (2008): Specchi del letterario: l'imagologia, Palermo, Sellerio.

SANTOS UnAmuno, Enrique (2006): «Las 'imágenes nacionales' como objeto de estudio: nación y guerras simbólicas. El caso español (1990-2006)», Norba. Revista de Historia, vol. 19, pp. 259283.

(2009): «De la Imagología a los ImageNation Studies: prolegómenos de una propuesta teórica», en Salvador Crespo et al. (eds.): Teoría y análisis de los discursos literarios. Estudios en homenaje al profesor Ricardo Senabre Sempere. Salamanca, Universidad, pp. 425-432.

- (2011): «Historia, Antropología y Estudios Literarios: aspectos de la estereotipia en Julio Caro Baroja», en Túa Blesa, Juan Carlos Pueo, Ángel Saldaña y Enric Sullà, eds., Pensamiento literario español del siglo XX, 5, Zaragoza, Anexos de Tropelías, pp. 219-244.

SAssi, Maria Michela (1988): La scienza dell'uomo nella Grecia antica, Turín, Bollati Boringhieri.

SMEED, John William (1985): The Theofrastan 'Character'. The History of a Literary Genre, Oxford / Nueva York, Clarendon Press.

TRAIMOND, Bernard (2004): «Prólogo», en Julio Caro Baroja: El mito del carácter nacional. Madrid: Editorial Caro Raggio, 11-29.

VAN DELFT, Louis (1993): Littérature et anthropologie. Nature humaine et caractère à l'âge classique, París, Puf. 